\title{
Verbose exponence: integrating the typologies of multiple and distributed exponence*
}

\author{
Matthew J Carroll
}

1st July 2021

\author{
To appear in Morphology
}

\begin{abstract}
Multiple exponence is the multiple marking of the same feature or category within a single word. Distributed exponence is the occurrence of morphological structure such that providing a precise interpretation of a category can only be determined after considering more than one morphological formative. I propose the term verbose exponence to capture the common ground between these phenomena, i.e. all situations involving multiple morphological formatives sensitive to some common information. From this definition, a typology based on informational overlap emerges with types of verbose exponence corresponding to types of set interactions. The typology incorporates known related phenomena, such as overlapping exponence, while providing a sophisticated framework for describing previously unnamed phenomena. This typology is naturally cast in set-theoretic terms and formal definitions are provided for all assumptions and points in the typology. Such an approach provides precise articulations of the typological space but also of morphological redundancy, a property often associated with multiple exponence.
\end{abstract}

Keywords: multiple exponence; distributed exponence; typology; set-theoretic morphology; redundancy

${ }^{*}$ I gratefully acknowledge the financial support of the British Academy Newton International Fellowship: A Typology of Distributed Exponence (NF160104) as well as the Endangered Language Documentation Programme Postdoctoral Fellowship (IPF0283) and the ARC Centre of Excellence for the Dynamics of Language. 


\section{Introduction}

Multiple exponence, also known as extended exponence (Matthews, 1974), is the marking of the same information multiple times in the word. Harris (2017) in her extensive discussion of the topic defines multiple exponence as in (1):

(1) Multiple (or extended) exponence is the occurrence of multiple realizations of a single feature, bundle of features, or derivational category in more than one position in a domain.

Harris exemplifies this with an example from Batsbi, a Nakh-Daghestanian language, as in (2). In this example there are three identical gender markers occurring in the same word. In this particular case, the forms are identical but more importantly the provide identical information.

(2) Batsbi

(Harris, 2017, 2)

$$
\begin{array}{lc}
\text { y-ox-y-o-y-an } & \text { k'ab } \\
\text { II.SG-rip-II.SG-PRS-II.SG-EVID dress(II).ABS }
\end{array}
$$

'Evidently she is ripping the dress.'

Distributed exponence is the co-occurrence of multiple formatives within a single word such that more than one formative is required to provide a fully specified reading of a feature or category (Caballero and Harris, 2012; Carroll, 2016; Harris, 2017). Consider the expression of the values of number in this partial paradigm, taken from Nen (Yam, Papuan) (Evans, 2015). In this example, there is no single morphological marker for any given value of number, i.e. PLURAL; rather, a PLURAL is marked through the combination of the prefix, yä, and the suffix, ngr. Said another way, the exponence of plural is distributed over the prefix and the suffix.

Table 1: 3rd person present forms of Nen tromngr 'be erected' (Evans, 2015, 568)

$\begin{array}{ll}\text { SINGULAR } & \text { y-trom-ngr } \\ \text { DUAL } & \text { yä-trom-aran } \\ \text { PLURAL } & \text { yä-trom-ngr } \\ \text { LARGE PLURAL } & \text { y-trom-aran }\end{array}$

What these two phenomena have in common is that the expression of content uses more formatives than is minimally required from a conceptual standpoint. In the simplest possible model, each paradigmatic contrast need only be indicated a single formative (Corbett, 2015; Bond, 2019). Yet in both multiple and distributed exponence, 
we can say that the exponence system is verbose in that it uses more formatives than strictly necessary from a system design perspective.

Harris (2017) defines multiple exponence in such a way to exclude distributed exponence from her discussion, however the two phenomena are clearly related. Both are characterised by multiple co-occurring morphological formatives, i.e. affixes, providing information about the same feature. Where these two examples differ is in the type of overlap regarding the information they provide. Multiple exponence involves identical information about a feature while distributed exponence involves a partial overlap in information. The argument of this paper is that by characterising the typological space as pertaining to informational overlap, i.e. verbose exponence, a typology emerges characterised by the natural types of set interactions, identity, subset and partial intersection, as well as by the degree of overlap. I then show how this more fine-grained approach produces a sophisticated typology integrating a range of complex previously unintegrated phenomena.

\subsection{How to read this paper}

The primarily approach of this paper is comparative. Its goal is to develop the set of variables for capturing the cross-linguistic variation of the phenomena under investigation (Bickel, 2007), in this case verbose exponence. What distinguishes this paper from a traditional typological paper is the formal metalanguage developed to make explicit the assumptions established in Section 2.

Section 2 of this paper is designed to lay out the assumptions underlying the typology in explicit terms. This section makes use of set-theoretic formalism to clarify exactly what constitutes the domain of investigation, explain how exponents have been identified and provides a framework for making explicit statements about the typological space. The paper assumes little knowledge of set-theory and all concepts are introduced along with careful precise prose. Readers only interested in the typological aspects may skip this section although it is necessary for understanding many of the analytical decisions made in subsequent sections.

Section 3 lays out the basic typology of verbose exponence. It establishes formal definitions for each of the three types of verbose exponence based on types of setinteractions. Section 4 shows how overlapping exponence and a range of related phenomena can be described as the interaction of verbose exponence with cumulative exponence. Finally, Section 5 explores the notion of redundancy or functional overlap as it applies to verbose exponence. I show that by using a sufficiently explicit metalanguage for language comparison, quantifiable measures of linguistic phenomena may be developed. 


\section{Assumptions}

Before we begin setting out the typology, it is necessary to state the assumptions underlying the analyses in Section 3. In this section, I provide definitions for the concepts used later as well as explicit statements about the means by which morphological informativeness has been identified.

The basic unit of analysis are words. A woRD, represented with $\omega$, is modelled as a 3 -tuple consisting of a WORDFORM $(W)$, a CELL $(\Sigma)$ and a LEXICAL INDEX $(l)$. This is formally presented in (3). The first line is the definition of the word and each subsequent line defines the relationship between the word and each of its component elements.

A word $(\omega)$ is defined as follows:

$$
\begin{aligned}
\omega & :<W, \Sigma, l> \\
\operatorname{wordform}(\omega) & =W \\
\operatorname{cell}(\omega) & =\Sigma \\
\operatorname{lexeme}(\omega) & =l
\end{aligned}
$$

A wordform $(W)$ is the phonological content of an inflected word. In this paper, wordforms are treated as a sequence of morphological formatives. For the sake of convenience, segmentation is taken from the original sources. ${ }^{1}$ To refer to a specific formative within a wordform, I will use the formative's form with an index representing its position in the wordform, starting from 1 . Thus $y_{1}$ refers to the first formative in (2), $o x_{2}$ to the second, $y_{3}$ to the third, etc. Indices are omitted where this does not lead to ambiguity.

A cell $(\Sigma)$ is a set of co-occurring feature values. I assume that morphosyntactic and semantic properties indicated by morphological structure can be captured by FEATURE VALUES established by a linguist on distributional grounds (Corbett, 2012). These are represented as FEATURE:VALUE in which values of a single feature share a common semantics or function and are mutually exclusive. For conciseness, only the values will be stated when unambiguous, i.e. PLURAL or PL implies NUMBER:PLURAL. Co-occurring feature values are treated as SETS. Inherent to this type of feature logic is the notion that each feature has a predefined set of values. We can formalise this as a function, $V$, which maps each feature, $\sigma$, to a set of values (4). I assume the feature systems as presented in the original sources, if features and values were not explicitly used in the original description they have been inferred from the available materials.

\footnotetext{
${ }^{1}$ It is worth noting that it is also possible to define formatives abstractively Blevins (2016). In this case, a wordform is defined as a group of phonological properties any subset of which can potentially be morphological active as defined by their distributions.
} 


$$
V(\sigma)=\left\{v_{1}, v_{2}, \ldots, v_{n}\right\}
$$

Finally, the lexical index $(l)$ is shared by all the words of a single lexeme. In this paper, this is represented with an uppercase label based on its English gloss, e.g. RIP. A more articulated approach might also make use of sets of features in order to represent a structured lexicon.

To exemplify, let us consider the Batsbi verb from (2). This inflected word is represented formally as in (5-a). This inflected word consists of three elements: the wordform represented as sequence of formatives (5-b), the cell represented as a set of feature values (5-c) and a lexical index (5-d).
a. $\quad \omega:<<y, o x, y, o, y, a n^{w}>,\{$ II, SG, PRS, EVID $\}, R I P>$
b. $\quad \operatorname{wordform}(\omega)=<y, o x, y, o, y, a n^{w}>$
c. $\quad \operatorname{cell}(\omega)=\{\mathrm{II}, \mathrm{SG}, \mathrm{PRS}, \mathrm{EVID}\}$
d. lexeme $(\omega)=R I P$

The lexical index is used to define a PARADIGM, conventionally represented as $\lambda$, as in (6).

$\operatorname{A~paRAdigm}(\lambda)$ is defined as:

$$
\lambda=\operatorname{para}(l)=\{\omega: \operatorname{lex}(\omega)=l\}
$$

The definition reads in plain English: a paradigm, $\lambda$, is all the inflected words $\omega$ which share the property of having an identical lexical index $l$. Thus the paradigm of our Batsbi word, i.e. para $(R I P)$, is all the inflected words $\omega$ which share the same lexical index, i.e. those that satisfy lexeme $(\omega)=R I P$. Note that this is a paradigm of words, i.e. both forms and their associated feature values. This is distinct from some other conceptions of paradigm, i.e. distinct form and content paradigms (Stump, 2016).

With this definition in hand we can begin to determine the feature values associated with individual formatives. The first step is to list the distribution of the formatives over the paradigm (7). This states that the distribution of a given formative, $a$, is all cells for all words both containing that formative and sharing the same lexical index. This essentially defines a list of every cell in the paradigm for each word containing the formative under question.

(7) The DISTRIBUTION of a formative, $a$, in a paradigm, $\lambda$, is defined as:

$$
\operatorname{dist}(a)=\{\operatorname{cell}(\omega): \omega \in \lambda, a \in \operatorname{wordform}(\omega)\}
$$

To illustrate, let us consider the distributions of the gender markers in the Batsbi 
Table 2: Partial paradigm of Batsbi gender markers

\begin{tabular}{lcc}
\hline & SG & PL \\
\hline I & v & b \\
II & $\mathbf{y}$ & d \\
III & $\mathbf{y}$ & $\mathbf{y}$ \\
IV & b & b \\
V & d & d \\
VI & b & d \\
VII & b & $\mathbf{y}$ \\
VIII & d & $\mathbf{y}$ \\
\hline
\end{tabular}

example from the beginning of the article. In this example, there are three markers which share an identical form and also share an identical distribution; this is listed in the partial paradigm presented in Table 2. From this table, we can see that Batsbi gender markers serve to indicate up to eight noun classes, here labelled with Roman numerals, crossed with two values of number. It is worth noting the many form syncretisms in which the same segment is repeated for multiple cells in the paradigm. With this in hand, we can state the distributions of each gender marker. For example the distribution of the gender marker $y$, $\operatorname{dist}(y)$, is the set of all cells in which $y$ occurs. This is listed in (8).

$$
\operatorname{dist}(y)=\{\{\mathrm{SG}, \mathrm{II}\},\{\mathrm{SG}, \mathrm{III}\},\{\mathrm{PL}, \mathrm{III}\},\{\mathrm{PL}, \mathrm{VII}\},\{\mathrm{PL}, \mathrm{VIII}\}\}
$$

We can also determine the distribution of a formative along any given dimension of a paradigm. We formalise this as dist $_{\sigma}$ (9). This reads: the distribution of some formative, $a$, with respect to some feature, $\sigma$, is all the values, $v$, of that feature which occur in $\operatorname{dist}(a)$ as defined above.

(9) The DISTRIBUTION of a formative with respect to a feature $(\sigma)$ is defined as:

$$
\operatorname{dist}_{\sigma}(a)=\{v: v \in V(\sigma), v \in \operatorname{dist}(a)\}
$$

For a concrete example, consider again the distribution of $y$ in our Batsbi example. This form has two dimensions which are relevant for its distribution, number and gender, thus it has two distinct dist $\sigma$ sets. These are listed in (10).

$$
\begin{array}{ll}
\text { a. } & \operatorname{dist}_{\mathrm{NUM}}(y)=\{\mathrm{SG}, \mathrm{PL}\} \\
\text { b. } & \operatorname{dist}_{\mathrm{GEND}}(y)=\{\mathrm{II}, \mathrm{III}, \mathrm{VII}, \mathrm{VIII}\}
\end{array}
$$

However, a formative is only informative about a given feature if narrows the set 
of total possible values. This is the PRINCIPLE OF INFORMATIVENESS and it states that a formative only provides information along a dimension if it occurs with a proper subset of the total values along that dimension. We formally define this as a set called $I_{\sigma}(11)$.

(11) The InFoRMATIVENESS ${ }^{2}, I$, of a formative with respect to a feature $(\sigma)$ is defined as:

$$
I_{\sigma}(a)=\left\{v: v \in \operatorname{dist}_{\sigma}(a), \operatorname{dist}_{\sigma}(a) \subset V(\sigma)\right\}
$$

Consider the distribution of the Batsbi $y$ gender marker once again. Its distribution with respect to gender is informative as its presence helps us narrow down our options for eight potential values to the set of four values (II, III, VII, VIII). However, the formative itself tells us nothing about number as it occurs in both values of number. We can see the dist $\sigma$ sets for $y$ in (12) and that one of these sets is empty.

$$
\begin{array}{ll}
\text { a. } & I_{\mathrm{GEND}}(y)=\{\mathrm{II}, \mathrm{III}, \mathrm{VII}, \mathrm{VIII}\} \\
\text { b. } & I_{\mathrm{NUM}}(y)=\{\emptyset\}
\end{array}
$$

I have used the term informativeness rather than exponence in this paper as it has a clear functional interpretation. Informativeness can be defined informally as what information does a language learner or hearer have about the (grammatical) meaning of a word given this formative. Morphological theories and frameworks make different assumptions as to how features are encoded, however, the concept of informativeness is, at least in its informal definition, interpretable regardless of the theoretical approach to exponence.

\section{Types of verbose exponence}

In the introduction, we defined verbose exponence informally as multiple co-occurring formatives providing a hearer information about the same feature or category. Given our model in (3), we can now define this explicitly as in (13).

\footnotetext{
${ }^{2}$ By defining informativeness with respect to dist $_{\sigma}$, this definition captures both situations where a formative occurs across all values of a given feature as well as situations where a feature is simply not relevant for that cell. Consider the example of a language in which aspect distinctions made in the indicative mood are never distinguished in the subjunctive. In this situation, the dist ${ }_{\text {ASPECT }}$ will be empty and thus its $I_{\mathrm{ASPECT}}$ will also be empty. I will note that this observation was pointed out to me by Olivier Bonami during the editorial process. Indeed taking this a step further, it is irrelevant how you describe this system using features from the perspective of informativeness. Either describing this as a syncretism between aspect values in the subjective or by having aspect not apply both result in an empty $I_{\sigma}$ since neither provide information regarding aspect.
} 
A word, $\omega$, is an eXample of VERBOSE EXPONENCE iff:

$$
\exists a, b \in W \exists \sigma \in F: I_{\sigma}(a) \cap I_{\sigma}(b) \neq \emptyset
$$

This reads as follows: some word, $\omega$, is an example of verbose exponence if and only if the following conditions are met. Firstly, that there exists two formatives, $a$ and $b$, within a wordform, $W$, of that word, $\omega$. Secondly, there exists some feature, $\sigma$, in the set of total features in the language, $F$, such that the intersection of $I_{\sigma}(a)$ and $I_{\sigma}(b)$ is not empty. In other words, both formatives provide information about the value of a shared feature.

I should point out at this point that this typological definition applies to words rather than to paradigms. Thus, this is a typology of words and not a typology of systems and a given paradigm may display words of multiple types of verbose exponence. And as discussed later, a given word may even display multiple types of verbose exponence.

Given this definition and what already have seen about Batsbi, it is trivial to demonstrate that Batsbi is an authentic example of verbose exponence. Let us go through the proof here to illustrate. Firstly, we have already established the informativeness of each of the $y$ gender markers (14-a). Given that the distribution of each formative is identical, the intersection of these three sets is also identical and non-empty (14-b). Thus, we have a clear example of verbose exponence of gender marking in the Batsbi verb presented in (2). Note, however, that under this definition the Batsbi example in (2) is not an example of verbose exponence of number marking.

$$
\begin{array}{ll}
\text { a. } & I_{\mathrm{GEND}}\left(y_{n}\right)=\{\mathrm{II}, \mathrm{III}, \mathrm{VII}, \mathrm{VIII}\} \\
\text { b. } & I_{\mathrm{GEND}}\left(y_{1}\right) \cap I_{\mathrm{GEND}}\left(y_{3}\right) \cap I_{\mathrm{GEND}}\left(y_{5}\right)=\{\mathrm{II}, \mathrm{III}, \mathrm{VII}, \mathrm{VIII}\}
\end{array}
$$

This definition of verbose exponence will serve as a typological base (Bond, 2012). The minimal definition of all examples in our typology. Any and all further examples to be included within our typology must minimally satisfy this definition. Thus, given our assumptions, a feature-based analysis and our definition here we can clearly determine whether a given example constitutes a data-point in our typology.

From this basic definition, a typology emerges based on types of set interaction between the respective $I_{\sigma}$ sets. From the logic of set interactions we have identity, subset and partial intersections, i.e. intersections which are neither identical nor subsets (Halmos, 1960; Partee et al., 1990). This third type we will refer to simply as intersecting when unambiguous.

The first and most straightforward type is where the set of values associated with each formative are identical (§ 3.1). These is what is known as multiple exponence, e.g. 
the Batbsi example in (2). The second type occur when one formative's $I_{\sigma}$ is a subset of the others. The most common examples of this type typically involve successively more specific markers, e.g. combining a non-singular marker with a dual marker (§ 3.2). Finally, the third type occur when the two formative's $I_{\sigma}$ sets partially intersect. This is what we are calling distributed exponence as in the Nen example in the introduction (§3.3).

\subsection{Identity of information}

The first type in our typology are instances where the information provided by each formative is identical. These are the types of canonical multiple exponence most commonly given in the literature. Given our model this type is defined as verbose exponence in which the $I_{\sigma}$ of each formative are identical (15).

(15) Verbose exponence within some word, $\omega$, may involve INFORMATION IDENTITY with respect to some feature, $\sigma$, also known as multiple exponence:

$$
\exists a, b \in W, \exists \sigma \in F: I_{\sigma}(a)=I_{\sigma}(b) \neq \emptyset
$$

To clarify, this definition reads: some word, $\omega$, is an example of information identity if and only if there are two formatives that occur within that word, such that each formative provides the same information, $I$, with regard to some feature, $\sigma$. In other words, that $I_{\sigma}(a)$ is equal to $I_{\sigma}(b)$ and that neither are empty.

We can return to our Batsbi example for a concrete example of this. And since these are all equal (16), this is unequivocally an example of verbose exponence with identity of values, i.e. multiple exponence.

$$
I_{\mathrm{GEND}}\left(y_{1}\right)=I_{\mathrm{GEND}}\left(y_{2}\right)=I_{\mathrm{GEND}}\left(y_{3}\right)=\{\mathrm{II}, \mathrm{III}, \mathrm{VII}, \mathrm{VIII}\}
$$

Harris (2017) and others discuss examples of multiple exponence in great detail and so I will not take additional space here to exemplify this further.

\subsection{Subset of information}

The second type in our typology involves verbose exponence where the information provided by one formative is a subset of the information provided by another formative in that word. In other words, the $I_{\sigma}$ sets of the formatives is one involving a proper subset (17).

Verbose exponence of a word, $\omega$, may involve INFORMATION SUBSET with respect 


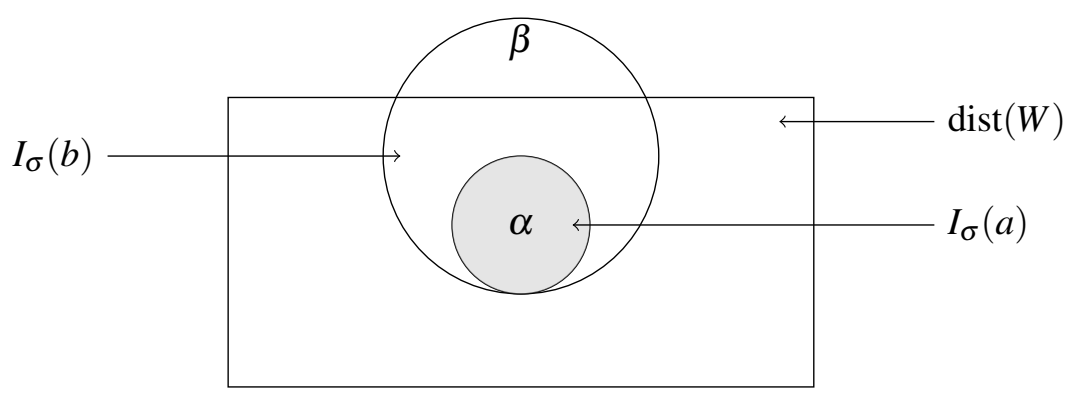

Figure 1: Schematic representation of information subset verbose exponence

to some feature, $\sigma$ :

$$
\exists a, b \in W, \exists \sigma \in F: I_{\sigma}(a) \subset I_{\sigma}(b), I_{\sigma}(a) \neq \emptyset
$$

The above reads that a word, $\omega$, is an example of information subset verbose exponence if there exists two formatives in a single word such that the set of values informed by one formative with respect to a given feature is a proper subset of the set of values informed by the other formative with respect to that same feature. Crucially, it excludes trivial cases where the $I_{\sigma}(a)$ is empty. In other words, the $I_{\sigma}$ of one formative is a proper subset $I_{\sigma}$ of another within the same word.

This is represented schematically in Figure 1 . We can see the $I_{\sigma}$ for at least one formative is informative beyond the features associated with the inflected word $\operatorname{dist}(W)$. The intersection is shaded in grey. The intersection is equal to $I_{\sigma}(a)$ and is contained as a subset of $I_{\sigma}(b)$. In this example $I_{\sigma}(a)$ is entirely within $\operatorname{dist}(W)$ although this need not necessarily be the case.

To exemplify, consider the expression of plural in Wipi, an Eastern Trans-Fly language from southern New Guinea, unrelated to Nen (Evans et al., 2017). For verbs in this language, number is marked through a combination of a prefix and suffix as presented in Table $3 .^{3}$ The prefixes also encode the person of the object as well as number although this is not relevant for our example. It is worth noting that this example demonstrates that sequential position cannot be used to predict informativeness.

Table 3: 1SG>3 PRS of Wipi 'to build' Anne Dondorp and Jae-Wook Shim (1997:37)

$\begin{array}{ll}\text { 'I build a house' } & \text { yo-ran-en } \\ \text { 'I build (two) houses' } & \text { a-ray-en } \\ \text { 'I build (three) houses' } & \text { a-ran-inon }\end{array}$

\footnotetext{
${ }^{3}$ Note that marking of dual in this paradigm is an example of distributed exponence that we will return to in Section 3.3.
} 


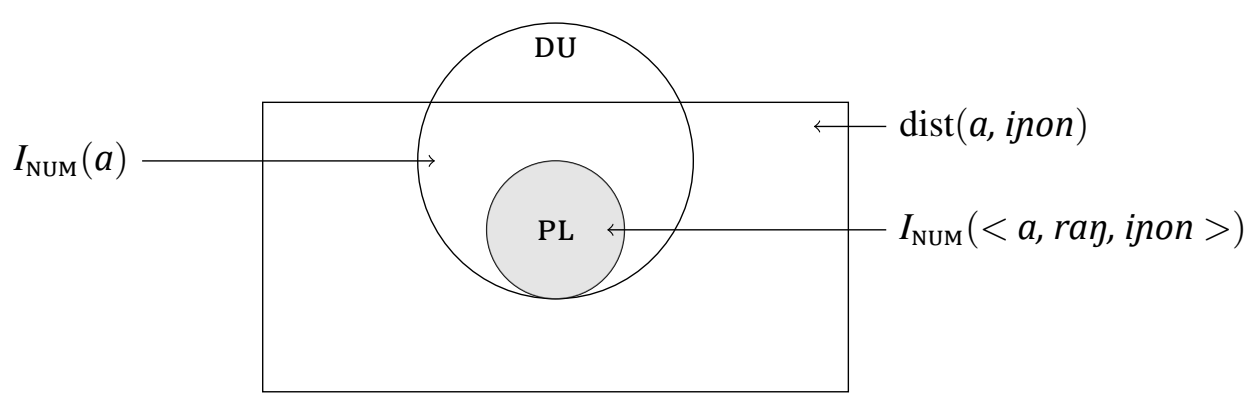

Figure 2: Diagram of redundancy of $I_{\mathrm{NUM}}$ sets for plural marking in Wipi

To start, let us prove this is a case of verbose exponence. The prefix provides information that the number value is either DUAL or PLURAL while the suffix is only used in the PLURAL (18-a) and (18-b). Since PLURAL occurs at the intersection of these two sets, we have verbose exponence (18-c).

$$
\begin{array}{ll}
\text { a. } & I_{\mathrm{NUM}}(a)=\{\mathrm{DU}, \mathrm{PL}\} \\
\text { b. } & I_{\mathrm{NUM}}(\text { inon })=\{\mathrm{PL}\} \\
\text { c. } & I_{\mathrm{NUM}}(a) \cap I_{\mathrm{NUM}}(\text { inon })=\{\mathrm{PL}\}
\end{array}
$$

Having established this is indeed verbose exponence, we can now determine what the relationship is between the two formatives with respect to number. Since the $I_{\sigma}$ of the suffix is a proper subset of the prefix (19), we know we have a case of information subset verbose exponence.

$$
\begin{array}{ll}
\text { a. } & \{\mathrm{PL}\} \subset\{\mathrm{DU}, \mathrm{PL}\} \\
\text { b. } & I_{\mathrm{NUM}}(a) \subset I_{\mathrm{NUM}}(\text { inon })
\end{array}
$$

This concrete example can be visualised in Figure 2 where we can clearly see the subset relation of the two sets and the syncretism across the domain of number for the prefix.

A common example of this kind of verbose exponence occurs when we have a default or an oblique marker occurring with a more specific affix. An example of this is the marking of non-absolutive cases in Nakh-Dagestanian languages, consider the noun paradigm of Archi forms of $\mathrm{ba}^{\complement} \mathrm{k}^{\prime}$ 'ram' in Table 4.

Cases in Archi are marked with up to three formatives. For example, genitive case is marked through the stem vowel, a stem thematic iri and the suffix $n$. Both the stem vowel and the stem thematic indicate that the case is a non-absolutive in the singular, that is they provide information that the word may be any of the non-absolutive cases (20-a)-(20-b). This compared to the genitive suffix $n$ which is only ever found marking genitive $(20-c)$. Thus, both the stem vowel and the stem suffix participate in value subset verbose exponence with the suffix $n(20-d)$. Note that additionally the stem 


\begin{tabular}{|c|c|c|}
\hline & SG & PL \\
\hline ABSOLUTIVE & $\mathrm{ba}^{\complement} \mathrm{k}^{\prime}$ & $\mathrm{ba}^{\complement} \mathrm{k}^{\prime}-\mathrm{ur}$ \\
\hline ERGATIVE & $b e^{\complement} k^{\prime}$-iri & $\mathrm{ba}^{\mathrm{C}} \mathrm{k}^{\prime}$-ur-čaj \\
\hline GENITIVE & $\mathrm{be}^{\complement} \mathrm{k}^{\prime}$-iri-n & $\mathrm{ba}^{\mathrm{S}} \mathrm{k}^{\prime}-\mathrm{ur}-\breve{c} \mathrm{e}-\mathrm{n}$ \\
\hline DATIVE & $\mathrm{be}^{\complement} \mathrm{k}^{\prime}$-iri-s & $\mathrm{ba}^{\complement} \mathrm{k}^{\prime}-\mathrm{ur}-\breve{c ̆ e}^{-s}$ \\
\hline CAUSAL & $b e^{\complement} k^{\prime}$-iri-šsi & $\mathrm{ba}^{\complement} \mathrm{k}^{\prime}-\mathrm{ur}-\breve{c} \mathrm{e}-\mathrm{s}: \mathrm{i}$ \\
\hline COMITATIVE & $\mathrm{be}^{\mathrm{S}} \mathrm{k}^{\prime}$-iri-tru & $\mathrm{ba}^{\mathrm{S}} \mathrm{k}^{\prime}-\mathrm{ur}-\mathrm{c} \mathrm{e}-\mathrm{t}: \mathrm{u}$ \\
\hline COMPARATIVE & $\mathrm{be}^{\complement} \mathrm{k}^{\prime}$-iri- $\chi \mathrm{ur}$ & $\mathrm{ba}^{\mathrm{f}} \mathrm{k}^{\prime}-\mathrm{ur}-\breve{c} \mathrm{e}-\chi \mathrm{ur}$ \\
\hline PARTITIVE & $b^{\complement} k^{\prime}-i r i-q^{\complement}$ is & $\mathrm{ba}^{\uparrow} \mathrm{k}^{\prime}-\mathrm{ur}-\breve{c} \mathrm{e}-\mathrm{q}^{\uparrow} \mathrm{i} \breve{s}$ \\
\hline SIMILATIVE & $b^{\complement} k^{\prime}-i r i-q^{\complement} d i$ & $b a^{\uparrow} k^{\prime}-u r-\breve{c e}-q^{\uparrow} d i$ \\
\hline SUBSTITUTIVE & $\mathrm{be}^{\complement} \mathrm{k}^{\prime}$-iri-kt'ena & $\mathrm{ba}^{\mathrm{f}} \mathrm{k}^{\prime}$-ur-če- $k \mathrm{t}^{\prime} \mathrm{ena}$ \\
\hline
\end{tabular}

Table 4: Paradigm of Archi grammatical cases for $b a^{\complement} k^{\prime}$ 'ram' (Bond et al., 2016, 26)

Table 5: 1 (EXCL) > 3SG perfective forms of Ngan'gi 'to hit' (Reid, 1990, 118-119)

SINGULAR 'I hit it.'

PluRAL 'We (PL.EXCL) hit it.' (4 or more) nge-rr-beny-da

DUAL 'We (DU.EXCL) hit it.' (2 only) nge-rr-beny-gu-da

TRIAL 'We (TR.EXCL) hit it.' (3 only) nge-rr-beny-gu-da-nime

vowel and the thematic is an example of value identity and so this is an example of how words may participate in multiple types of verbose exponence.
a. $I_{\mathrm{CASE}}\left(b e^{\complement} k^{\prime}\right)=\{$ ERG, GEN, DAT, CAUS, COM, COMP, PART, SIM, SUB $\}$
b. $\quad I_{\text {CASE }}($ iri $)=\{$ ERG, GEN, DAT, CAUS, COM, COMP, PART, SIM, SUB $\}$
c. $I_{\mathrm{CASE}}(n)=\{\mathrm{GEN}\}$
d. $\quad I_{\mathrm{CASE}}(n) \subset I_{\mathrm{CASE}}\left(b e^{\S} k^{\prime}\right)=I_{\mathrm{CASE}}($ iri $)$

Another example comes from the marking of number in verbs in Ngan'gi (also known as Ngan'gityemerri), a southern Daly language spoken in the Daly River area of northern Australia. As visible in Table 5, number has four distinct values: singular, dual, trial and plural, and is marked for subjects up to three times on the verb (Reid, 1990,118). In the singular, it is unmarked and in the plural it is marked through the 'plural' marker $r r$. Rather interestingly, dual is marked through a combination of what is labelled 'plural' marker and what is called the 'dual' marker gu, whilst the trial is marked through a combination of the 'plural' marker, the 'dual' marker and then the 'trial' marker nime.

Under our approach, this is a case of three-way value subset exponence. The presence of the formative $r r$ tells us that this word is either DUAL, TRIAL or PLURAL (21-a). The formative $g u$ tell us that this word is either DUAL or TRIAL (21-b). Finally, the for- 
mative nume is the most specific and tells us, when it occurs, that it is TRIAL (21-c). Thus the information provide by nime is a subset of that provided by $g u$ and it in turn is a subset of that provided by $r$. Thus, when more than one co-occur we have an example of value subset verbose exponence (21-d).
a. $\quad I_{\mathrm{NUM}}(r r)=\{\mathrm{DU}, \mathrm{TRI}, \mathrm{PL}\}$
b. $\quad I_{\mathrm{NUM}}(g u)=\{\mathrm{DU}, \mathrm{TRI}\}$
c. $I_{\mathrm{NUM}}($ nime $)=\{\mathrm{TRI}\}$
d. $\quad I_{\mathrm{NUM}}($ nime $) \subset I_{\mathrm{NUM}}(g u) \subset I_{\mathrm{NUM}}(r r)$

\subsection{Distributed exponence}

Distributed exponence is the final type and involves $I_{\sigma}$ sets which intersect and yet neither set is equal to nor a subset of the other. This is formalised in (22).

(22) Verbose exponence in some word, $\omega$, may involve other types of INFORMATION INTERSECTION $^{4}$ with respect to some feature, $\sigma$ :

$$
\exists a, b \in W, \exists \sigma \in F: I_{\sigma}(a) \cap I_{\sigma}(b) \neq \emptyset, I_{\sigma}(a) \nsubseteq I_{\sigma}(b), I_{\sigma}(b) \nsubseteq I_{\sigma}(a)
$$

The definition in (22) reads: distributed exponence occurs where we have two formatives within a word for whom there is a single feature, $\sigma$, such that the information they provide with respect to that feature, $I_{\sigma}$, has a non-empty intersection and that the $I_{\sigma}$ of neither formative is a subset of the other. In this way, distributed exponence is the 'elsewhere' case of verbose exponence with respect to values and can be rather succinctly represented visually as in 3 .

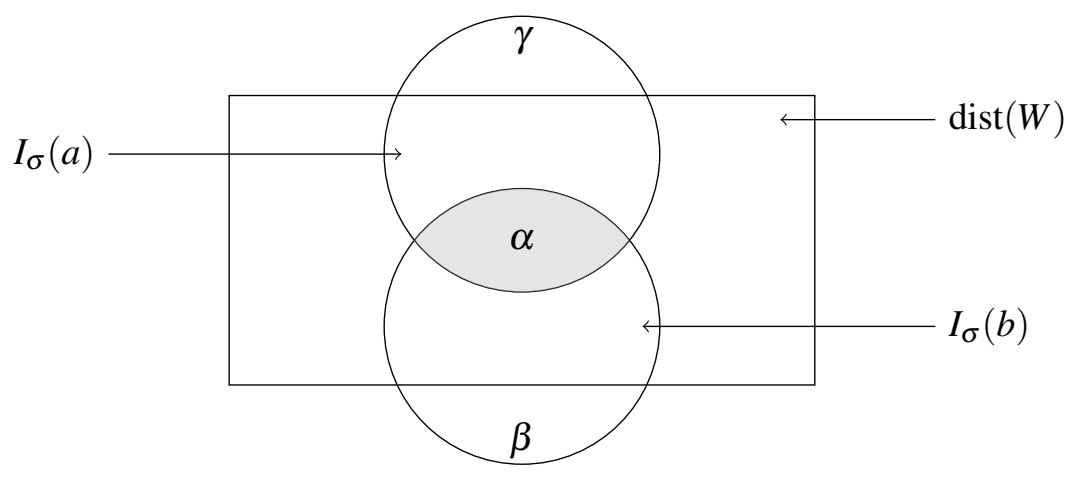

Figure 3: Schematic representation of distributed exponence

\footnotetext{
${ }^{4}$ Also known as DISTRIBUTED EXPONENCE.
} 
Yam languages, of which Nen is a member, are notable for the extent of their distributed exponence (Carroll, 2020). In the partial paradigm presented in Table 1, we saw that each of the values of number are indicated through distributed exponence. To help illustrate our definition, let us go through the proof for determining this for plural. Firstly, there are two non-stem formatives in the inflected word yä-trom-ngr (23-a). The prefix yä informs us that the final value must be either DUAL or PLURAL (23-b). The suffix ngr informs us that the final value must be either SINGULAR or PLURAL. Since PLURAL is the only value at the intersection of these two sets, we can unambiguously determined that the final inflected word must indicate PLURAL (23-d). And finally, since neither of these sets are a subset or equal to each other (23-e)-(23-f) this is distributed exponence as our definition shows. This can be represented visually as in 4.
a. $\quad y \ddot{a}, n g r \in<y$, trom, ngr $>$
b. $\quad I_{\mathrm{NUM}}(y \ddot{a})=\{\mathrm{DU}, \mathrm{PL}\}$
c. $I_{\mathrm{NUM}}(n g r)=\{\mathrm{SG}, \mathrm{PL}\}$
d. $\quad I_{\mathrm{NUM}}(y \ddot{a}) \cap I_{\mathrm{NUM}}(n g r)=\{\mathrm{PL}\}$
e. $I_{\mathrm{NUM}}(y \ddot{a}) \not \subset I_{\mathrm{NUM}}(n g r)$
f. $\quad I_{\mathrm{NUM}}(n g r) \not \subset I_{\mathrm{NUM}}(y \ddot{a})$

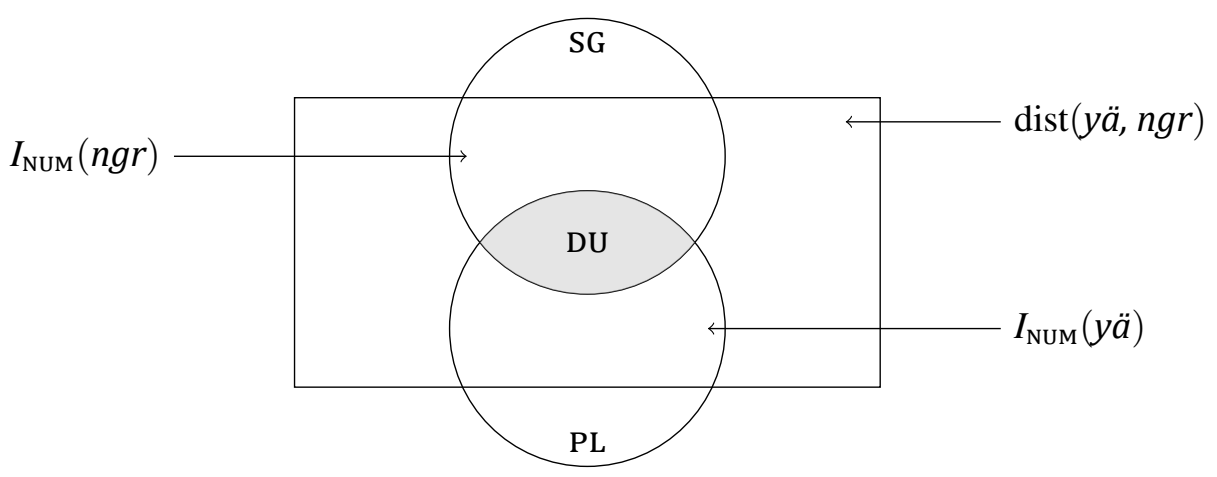

Figure 4: Distributed exponence of PLURAL in Nen tromngr

The Nen example is one of the most complete examples of distributed exponence in that each value of number is distributed exponence. A more typical pattern involves just a single value of a feature being marked in this way such as in dual marking in our Wipi example from Table 3. Dondorp and Shim (1997) analyse this as involving a non-singular prefix in combination with a non-plural suffix, where plural means three or more. Through a process of semantic unification, the dual value interpretation is derived. Regardless of the analysis, the most specific reading of number, dual, is only 
possible once one considers both of the formatives in question, and thus we have distributed exponence.

To illustrate, let us go through the expression of DUAL in Wipi in a similar manner to what we did for PLURAL. For the sake of exposition, let us assume that we have already proven DUAL is verbose exponence and focus on the relationship between the two formatives. First, the dist for both formatives are presented (24-a)-(24-b). From this we can derive their respective $I_{\sigma}$ sets with respect to number (24-c)-(24-d). Since these intersect and the intersection is not empty (24-e) and neither is a subset of the other (24-f)-(24-g), we have a genuine case of distributed exponence according to our definition.

$$
\begin{array}{ll}
\text { a. } & \operatorname{dist}(a)=\{\{3, \mathrm{DU}\},\{3, \mathrm{PL}\}\} \\
\text { b. } & \operatorname{dist}(e n)=\{\{\mathrm{DU}\},\{\mathrm{SG}\}\} \\
\text { c. } & I_{\mathrm{NUM}}(a)=\{\mathrm{DU}, \mathrm{PL}\} \\
\text { d. } & I_{\mathrm{NUM}}(e n)=\{\mathrm{DU}, \mathrm{SG}\} \\
\text { e. } & \{\mathrm{DU}, \mathrm{PL}\} \cap\{\mathrm{DU}, \mathrm{SG}\}=\{\mathrm{DU}\} \\
\text { f. } & I_{\mathrm{NUM}}(a) \nsubseteq I_{\mathrm{NUM}}(e n) \\
\text { g. } & I_{\mathrm{NUM}}(e n) \nsubseteq I_{\mathrm{NUM}}(a)
\end{array}
$$

Another example comes from the marking of neuter gender in the plural forms of demonstratives in Ngarnka (Osgarby, 2014), a Mirndi language spoken in the Barkly Tableland of Northern Australia. Consider the expression of the plural neuter forms in Table 6 which is marked through the combination of the prefix, $n a$, and the suffix $j a$. The prefix shares its form with the feminine gender while the suffix shares its form with the masculine gender. From our perspective, the expression of neuter gender in the plural is a case of distributed exponence as neither formative alone is sufficient to determine the gender.

Table 6: Ngarnka distal absolutive demonstratives (Osgarby, 2014, 108)

\begin{tabular}{llll}
\hline & SG & DL & PL \\
\hline MASC & ni-yangka & ni-yangka-wulu & ni-yangka-kuny-ja \\
NEU & na-yangka & na-yangka-wulu & na-yangka-kuny-ja \\
FEM & na-yangka & na-yangka-wulu & na-yangka-kuny-a \\
VEG & ma-yangka & ma-yangka-wulu & ma-yangka-kuny-ma \\
\hline
\end{tabular}

Given our definition, it is relatively straightforward to determine this constitutes a genuine example of verbose exponence. Let us go through the definition starting with gender. First we choose two formatives from the word, let us choose $n a$ and $j a$. Obviously, these both occur in the same wordform (25-a). The are both informative 
with regards to gender (25-d)-(25-e). And since they have a non-empty intersection for gender (25-f), this is unequivocally an example of verbose exponence as defined in (13). Further, since neither is equal to nor a subset of the other (25-g)-(25-h) this is a case of distributed exponence.
a. $\quad n a, j a \in<n a$, yangka, kuny, ja $>$
b. $\operatorname{dist}_{\mathrm{GEND}}(n a)=\{\mathrm{NEU}, \mathrm{FEM}\}$
c. $\quad \operatorname{dist}_{\mathrm{GEND}}(j a)=\{\mathrm{MASC}, \mathrm{NEU}\}$
d. $I_{\mathrm{GEND}}(n a)=\{\mathrm{NEU}, \mathrm{FEM}\}$
e. $\quad I_{\mathrm{GEND}}(j a)=\{\mathrm{MASC}, \mathrm{NEU}\}$
f. $\quad I_{\mathrm{GEND}}(n a) \cap I_{\mathrm{GEND}}(j a)=\{\mathrm{NEU}\}$
g. $\quad I_{\mathrm{GEND}}(n a) \nsubseteq I_{\mathrm{GEND}}(j a)$
h. $\quad I_{\mathrm{GEND}}(j a) \nsubseteq I_{\mathrm{GEND}}(n a)$

\section{Verbose exponence in higher dimensionality}

So far we have examined verbose exponence operating with respect to a single feature. However as we know, a formative might provide information about multiple distinct features, i.e. person and number, through a phenomenon known as cumulation or cumulative exponence (Matthews, 1974). For example in Sentani, a language spoken in the Lake Sentani region near Jayapura in Indonesian Papua, object agreement is marked twice on the verb in the presence of the aspect marker (26). Crucially for our point, it is marked for both number and person. Thus under our criteria this is an example of verbose exponence, or more precisely multiple exponence, of both person and number.

(26) Sentani

(Cowan, 1965, 35)

hab-aj-ən-ko-k-əm-be

hit-1PLS-2PLO-ASP-AOR-2PLO-IND

'We have hit you (pl).'

It need not necessarily be the case that cumulative exponence aligns the same in each of the formatives participating in verbose exponence. In Yei, a language distantly related to Nen also spoken in Indonesian Papua, we see both the prefix and suffix indicating number agreement, through distributed exponence, yet only the prefix marks person (27). So we have distributed exponence of number marking interacting with cumulated marking of person and number on the prefix. 
əd $\mathrm{y}$-əma-i

3NOM 3.NPL-sit-NSG

'They (2) are sitting.'

This is similar to what has been called partially superfluous multiple exponence in which we have multiple exponence intersecting with cumulative exponence such that one formative marks an additional feature not indicated by the other (Caballero and Harris, 2012). An example from this comes from Turkish presented in (28). In this example past tense is marked on both suffixes, while the suffix $k$ also marks agreement.

\section{Turkish}

(Coates, 2000, 623)

bul-du-k

find-PST-1.PL.PST

'We found'

The parallels between these two examples should be clear, in each case we have verbose exponence interacting with cumulative exponence. The difference between these two examples is the type of overlap with respect to the verbosely marked feature. By taking informational overlap as definitional, i.e. verbose exponence, we are able to integrate these types of multiple exponence into a single typology with the various types discussed in the previous section without loosing their distinctiveness.

To capture generalisations at this level of generality we need to posit a new set which captures which features a formative provides information for. We will call this dim. This is simply a list of the features that a given formative provides information. We can define this formally in (29).

(29) The dimensions on which a formative provides informations, dim, is defined as:

$$
\operatorname{dim}(a)=\left\{\sigma \in F: I_{\sigma}(a) \neq \emptyset\right\}
$$

This simply reads that $\operatorname{dim}(a)$ is all features, $\sigma$, for which the formative, $a$, is informative, i.e. all those features for which $I_{\sigma}$ is not empty.

Let us consider Ngkarnka as a concrete example. We will be using the neutral plural demonstrative from the paradigm in Table 6 focusing on the the $n i$ prefix and the $j a$ suffix. The distributions of these affixes are listed in (30).
a. $\operatorname{dist}(n i)=\{\{\mathrm{SG}, \mathrm{MASC}\},\{\mathrm{DU}, \mathrm{MASC}\},\{\mathrm{PL}, \mathrm{MASC}\}\}$ 


\section{b. $\operatorname{dist}(j a)=\{\{\mathrm{PL}, \mathrm{MASC}\},\{\mathrm{DU}, \mathrm{MASC}\}\}$}

The ni prefix occurs in all three numbers across the masculine gender, in other words it is informative about masculine gender only and offers us no information regarding number. Whereas, $j a$ only occurs in masculine gender but also gives us information regarding number, i.e. that it is either dual or plural. We can formalise these as a series of $I_{\sigma}$ sets (31).
a. $I_{\mathrm{GEND}}(n i)=\{\mathrm{MASC}\}$
b. $\quad I_{\mathrm{NUM}}(n i)=\emptyset$
c. $I_{\mathrm{GEND}}(j a)=\{\mathrm{MASC}\}$
d. $\quad I_{\mathrm{NUM}}(j a)=\{\mathrm{DU}, \mathrm{PL}\}$

From this, we can derive their dim sets, i.e. all the features, $\sigma$, for which there exists a non-empty $I_{\sigma}$ for that formative. For $n a$, this is only gender (32-a). For the suffix $j a$ this is both gender and number (32-b).

$$
\begin{array}{ll}
\text { a. } & \operatorname{dim}(n i)=\{\text { GEND }\} \\
\text { b. } & \operatorname{dim}(j a)=\{\text { GEND, NUM }\}
\end{array}
$$

With this in hand we can discuss types of multidimensional interactions in a parallel way to what we did for a given dimension. This first type is verbose exponence where the sets of feature associated with the relevant formatives are identical. In other words, the formatives display equal dim sets (33).

Verbose exponence within some word, $\omega$, may involve FEATURAL IDENTITY:

$$
\exists a, b \in W: \operatorname{dim}(a)=\operatorname{dim}(b)
$$

This reads, that instances of verbose exponence may be classified as featural identity if there are two co-occurring formatives within a wordform and those formatives are informative about the exact same set of features, i.e. that the dim of one formative is exactly equal to the dim of the other regardless of the information that they provide about these features.

We have already seen this in the Sentani example (26). In this example, we have two formatives $\partial n$ and $\partial m$ in the same word (34-a). Note that $2 m$ is almost certainly phonologically conditioned by the following labial segment however we shall treat them as separate for the discussion here. Each one is informative with respect to both person and number (34-b)-(34-c) and thus their dim sets only contain person and number (34-d)-(34-e). Since these are identical (34-f) this matches our definition for featural identity in (33). 

a. $\quad$ on, $, \mathrm{m} \in<\mathrm{hab}, a j, n, k o, k, m, b e>$
b. $\quad I_{\mathrm{NUM}}(n)=\{\mathrm{PL}\}, I_{\mathrm{PER}}(n)=\{2\}$
c. $I_{\mathrm{NUM}}(m)=\{\mathrm{PL}\}, I_{\mathrm{PER}}(n)=\{2\}$
d. $\operatorname{dim}(n)=\{$ PER, NUM $\}$
e. $\operatorname{dim}(m)=\{$ PER, NUM $\}$
f. $\quad \operatorname{dim}(n)=\operatorname{dim}(m)$

More interesting are examples in which the sets of features indicated by one formative is a proper subset of another. Formally, this defined in (35).

Verbose exponence within some word, $\omega$, may involve FEATURAL SUBSET:

$$
\exists a, b \in W: \operatorname{dim}(a) \subset \operatorname{dim}(b), \operatorname{dim}(a) \neq \emptyset
$$

This reads, that instances of verbose exponence may be classified as featural subset if there are two formatives within a single word such that the set of features for which one formative is informative, $\operatorname{dim}(a)$, is a subset of the set of feature for which the other is informative, $\operatorname{dim}(b)$. This can be viewed diagrammatically as in 5 . We can clearly visualise how the set of features of one formative must be a subset of the other and the total set of features must all be a subset of the features indicated by that word.

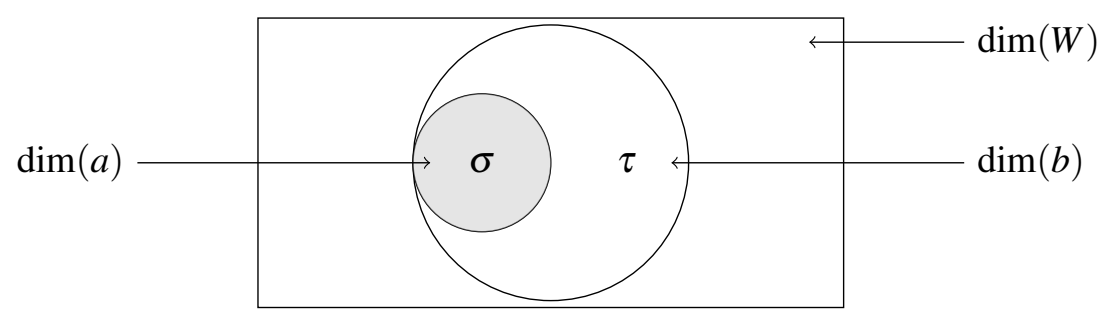

Figure 5: A schematic representation of featural subset

For a real world example, let us return to our example from Yei (27). Without going through the entire paradigm of the Yei verb, the set of values informed by each formative matches the gloss from the example. Thus, the set of features that they mark in presented in (36-a)-(36-b). This is person and number for $g$ and just number for $y$. Thus since the set containing only NUM, i.e. the set of features indicated by $y$, is a subset of the set containing PER and NUM, i.e. the set of features indicated by $g$ (36-c), then this matches our definition of feature subset verbose exponence (36-d).
a. $\operatorname{dim}(g)=\{$ PER, NUM $\}$
b. $\quad \operatorname{dim}(y)=\{\mathrm{NUM}\}$
c. $\quad\{$ NUM $\} \subset\{$ PER, NUM $\}$ 


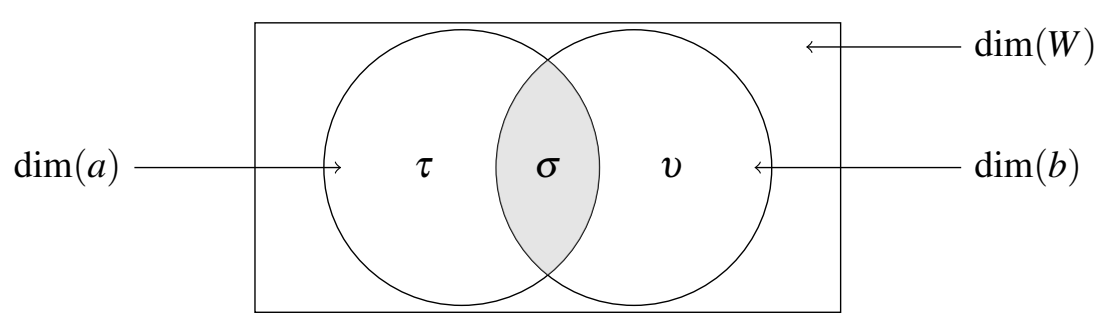

Figure 6: A schematic representation of featural overlap
d. $\quad \operatorname{dim}(y) \subset \operatorname{dim}(g)$

From this perspective, Yei is identical to the Turkish example, in which the dim of one formative is a proper subset of another co-occurring formative (37-a)-(37-d). However, what makes them distinct is their $I_{\sigma}$ rather than their $\mathrm{dim}$.
a. $\operatorname{dim}(d u)=\{$ PER, NUM $\}$
b. $\quad \operatorname{dim}(k)=\{\mathrm{NUM}\}$
c. $\quad\{$ TNS $\} \subset\{$ TNS, NUM $\}$
d. $\operatorname{dim}(d u) \subset \operatorname{dim}(k)$

Parallel to verbose exponence along a single dimension we have a third type involving the intersection relation. We can define this as verbose exponence in which the sets of features associated with one formative is neither equal to nor a subset of another. This is formulated in (38).

(38) Verbose exponence within some word, $\omega$, may involve FEATURAL OVERLAP:

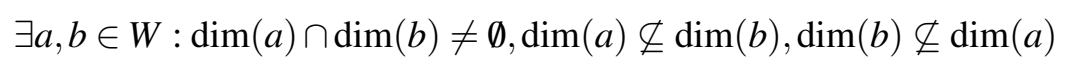

This reads, that instances of verbose exponence may be classified as featural overlap if there are two formatives within that word such that the set of features for which the formative provides information for, $\operatorname{dim}(A)$, has a non-empty intersection with set of features associated with the other formative, $\operatorname{dim}(b)$. Furthermore, neither is equal to or a subset of the other. We can visualise this relationship as per Figure 6 in which both the intersection at the point of $\alpha$ is clearly visible and the shaded intersection, $i$, is clearly a proper subset of both dim sets.

Note that featural overlap also includes all examples of overlapping exponence as presented by both Matthews (1974) and Harris (2017). The only distinction is that the set of feature values that each formative is sensitive to does not need be identical for 
any of the features they inform. Caballero and Harris (2012) exemplify overlapping exponence with an example from Filomeno Mata Totonco reproduced here in (39). In this example there are three formatives encoding second person. In addition, the stem encodes the lexical information, the first suffix also encodes progressive and the second suffix encodes singular. For the purposes of our illustration, we will exclude the stem information from our analysis.

Filomeno Mata Totonco

(McFarland, 2009) cited in (Caballero and Harris, 2012, 175)

tan-paa-ti

come.2-2.PROG-2.SG

'you (sg) are coming.'

Again, for the sake of exposition we will assume that the glosses provided in this example are accurate with respect to their informativeness. Thus we can abstract away to the sets of features from this list of values (40-a)-(40-b). These are clearly redundant exponence as the two sets of features do intersect (40-c). Yet we can see that this is a case of featural overlap since while they do intersect, they do not exist in a subset relation to each other nor are they equal (40-d)-(40-e).

$$
\begin{array}{ll}
\text { a. } & \operatorname{dim}(p a a)=\{\text { PER, ASP }\} \\
\text { b. } & \operatorname{dim}(t i)=\{\text { PER, NUM }\} \\
\text { c. } & \{\text { PER, ASP }\} \cap\{\text { PER, NUM }\}=\{\text { PER }\} \\
\text { d. } & \operatorname{dim}(p a a) \not \subset \operatorname{dim}(t i) \\
\text { e. } & \operatorname{dim}(t i) \nsubseteq \subset \subset \operatorname{dim}(t i)
\end{array}
$$

It should be apparent how verbose exponence interacting with multiple instances cumulation can easily result in extremely complex networks of exponence. Let us consider the Ngarnka example more closely here. In example (25), we established that expression gender by the affixes $n i$ and $j a$ in the word nayangkakunyja was an example of distributed exponence. However, it is also a case of featural subset since the suffix $j a$ also marks number, as we have already seen repeated here (41-a)-(41-c). However, number is also marked with the suffix kuny indicating plural, thus kuny and ja also exist in an instance of verbose exponence, this time multiple exponence (41-d). Yet these two also participate in featural subset exponence since, as we have seen, the suffix also marks gender (41-f).
a. $\operatorname{dim}(n i)=\{$ GEND $\}$
b. $\operatorname{dim}(j a)=\{$ GEND, NUM $\}$ 

c. $\quad \operatorname{dim}(n i) \subset \operatorname{dim}(j a)$
d. $\quad I_{\mathrm{NUM}}(j a)=I_{\mathrm{NUM}}(k u n y)$
e. $\operatorname{dim}($ kuny $)=\{\mathrm{NUM}\}$
f. $\quad \operatorname{dim}(k u n y) \subset \operatorname{dim}(n a)$

\section{Redundancy and verbose exponence}

Multiple exponence is often discussed in relation to redundancy (Caballero and Kapatsinski, 2015). In this section I show how the perspective of verbose exponence taken in this paper provides a sophisticated definition of morphological redundancy arising from repeated information. This definition results in two distinct types of redundancy, bilateral and unilateral. It is also sufficiently precise to allow for a quantification of redundancy.

Informally, redundancy refers to some element of a system that is unnecessary or in surplus to some requirements. From our perspective, if a formative makes no informational contribution, given all other formatives in the same word, it is REDUNDANT. This general functional conception of redundancy aligns to definitions from a range of disciplines. In information theory, redundancy is a crucial concept and might be characterised as the 'amount of structural deletion that is possible without loss of meaning' (Partridge, 1981). Similar definitions hold for redundancy in ecological systems; Lawton and Brown (1994) define a redundant species as one that can be removed from an ecosystem without changing other aspects of that ecosystem. Work on genetic redundancy is perhaps closest to the discussion here. Nowak et al. (1997) defines genetic redundancy as the situation of two or more genes performing the same or overlapping function such that the inactivation of one of these genes has little to no effect on the phenotype. A parallel diagnostic for morphological redundancy could be stated for language: If during a communicative speech event some formative were to be disrupted, perhaps through a speech error or occurring at the same time as an outside noise, and a hearer was still able to unambiguously recover that information, than the disrupted formative should be considered redundant based on our definition.

To exemplify, let us return to the marking of trial number in Ngan'gi in which we have successively more specific number markers repeated here in (42).

Ngan'gi (Reid, 1990, 119)

ngarrgu-nime nge-rr-beny-gu-da-nime

1.DU-TR 1-PL.EXCL-bash.PFV-DU-hit-TRI

'We (TR.EXCL) hit it.' (3 only) 
To reiterate, trial number is marked with the combination of what is labelled a 'plural' marker, $r r$, a 'dual' marker, $g u$, and then a 'trial' marker, nime. Yet for the purposes of providing information regarding, the plural and dual markers provide a hearer with no additional information given the presence of nime. In terms of our diagnostic, if a hearer of the language failed to hear either or both of the first two number markers, they would still be able to unambiguously infer the number value of the word so long as they heard the final nime. In this way, the plural and dual markers in this word are redundant. Note that these markers are not redundant given the entire Ngan'gi system, just in this particular word.

This redundancy is made especially clear when we look at those forms which have object agreement which compete for the same slot in the verbal template as the dual marker. In example (43), we have a trial marked verb with a first person object. The object marker ngi occurs where we would expect the dual marker, yet the verb still unambiguously refers to trial number. In this case, it is not only a hypothetical scenario but one attested in the grammar.

Ngan'gi (Reid, 1990, 224)

alayi warrakma kinya werrme-ngi-pul-nime-tye

mother three this 3.PL.hands-PST.IPFV-1.SG.OBJ-clear-TRI-PST

'These three (classificatory) mothers of mine used to wash me.'

\subsection{Defining redundancy}

Given our model, we can formally define morphological redundancy as in (44):

A formative $a$ in $W$ is REDUNDANT with respect to some feature $\sigma$ iff:

$$
I_{\sigma}(a) \supseteq \bigcap_{b \neq a} \operatorname{dist}_{\sigma}(b)
$$

This reads that a formative is redundant if and only if its $I_{\sigma}$ is a superset of the intersection of the distributions with respect to that feature of all formatives, $b$, which occur within the same word and which are not $a$. Note that this is defined with respect to the most specific reading possible given all other formatives within that word, i.e. the intersection of all other formative's dist $\sigma$. Consider again the redundancy diagram for unilateral paradigmatic redundancy in Wipi modified and presented here again in 7. In this case there are two affixes marking number, however, it should be clear to the reader that one is more informative than the other, inon, while the prefix $a$ does not 


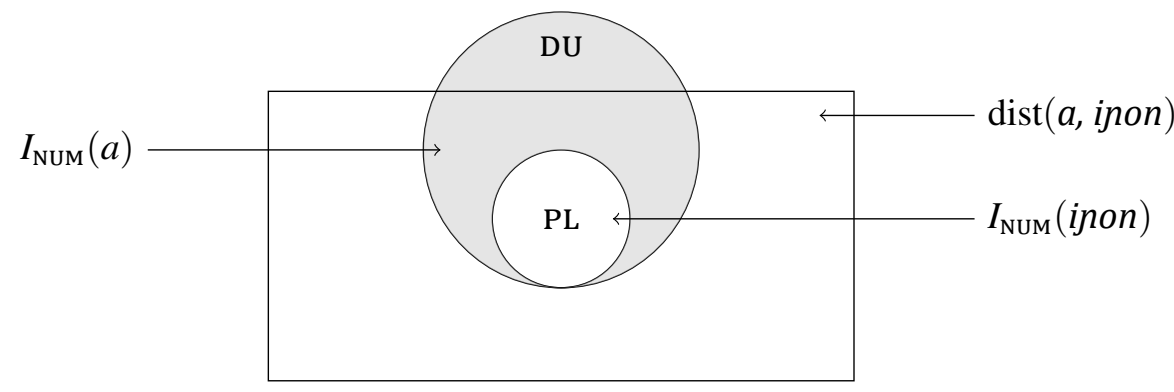

Figure 7: Diagram of partial redundancy of $I_{\mathrm{NUM}}$ relations for plural marking in Wipi

contribute information. ${ }^{5}$

From this definition, we can identify two distinct sub-types of redundancy: bilateral and unilateral. In cases of bilateral redundancy, each formative is redundant given the other formatives, i.e. there is a symmetrical relation with regards to information. While in unilateral redundancy, their is an asymmetrical redundancy relationship.

All instances of bilateral redundancy are also instances of canonical multiple exponence. Consider again the Batsbi example (45) in which the information provided by each formative is identical. Thus, each gender marker should be considered redundant given any other gender marker.

a. Batsbi

(Harris, 2017, 2)

$$
\begin{array}{ll}
\text { y-ox-y-o-y-an } & \text { k'ab } \\
\text { II.SG-rip-II.SG-PRS-II.SG-EVID dress(II).ABS }
\end{array}
$$

'Evidently she is ripping the dress.'

$$
\text { b. } \quad I_{\mathrm{GEND}}\left(y_{1}\right)=I_{\mathrm{GEND}}\left(y_{2}\right)=I_{\mathrm{GEND}}\left(y_{3}\right)=\{\mathrm{II}, \mathrm{III}, \mathrm{VII}, \mathrm{VIII}\}
$$

Compare this to our Ngan'gi example from (42). In the Ngan'gi example, it is clear that there is a directionality to the redundancy. The suffix nime is not redundant and its presence makes both other number affixes redundant as we have already seen.

\subsection{Quantifying redundancy}

So far we have seen how redundancy can be defined with respect to a given a given feature in a given word. However, it is rare to find a formative which is redundant in all the environments in which it occurs. Take for instance our Ngan'gi example (42), in the trial the dual and plural markers are redundant. However, in the dual contexts the

\footnotetext{
${ }^{5}$ Note that here we are talking about redundancy resulting from verbose exponence, i.e. repeated information. Absolute redundancy, i.e. a non-functioning, is simply defined as a formative which provides no information. This we would define as a formative having only empty $I_{\sigma}$ sets.
} 
dual marker is non-redundant and plural marker is redundant. Thus, it makes sense to provide a measure of a formative's redundancy across various domains.

We can quantify a formative's redundancy as the ratio of the number of associated redundant features or values to the total associated feature values for a given formative across the paradigm. This ratio is the REDUNDANCY VALUE of a formative which we will represent as $\bar{R}$. Informally, we can formulate this general definition of a formatives redundancy value as the fraction of redundant contexts over the total number of contexts of a formative (46).

Calculating a formatives REDUNDANCY VALUE $\bar{R}(a)$ :

$$
\bar{R}(a)=\frac{\mid\{\text { words where a is redundant }\} \mid}{\mid\{\text { words where a occurs }\} \mid}
$$

This can be defined with respect to the a specific feature, i.e. $\bar{R}_{\sigma}(47)$. This definition states that the redundancy value, $\bar{R}$ of a formative, $a$, with respect to some feature, $\sigma$, can be defined as a ratio of words where $a$ is redundant with respect to that feature to all the words where it occurs. The way we capture that ratio is with cardinality, i.e. number of elements in the set, and this is represented by the vertical bars.

$$
\bar{R}_{\sigma}(a)=\frac{\left|\left\{\omega: I_{\sigma}(a) \supset \bigcap \operatorname{dist}_{\sigma}(b)\right\}\right|}{|\{\omega: a \in W\}|}
$$

To exemplify let us consider the $a$ prefix, i.e. the non-singular, in the expression of number from the Wipi example in Table 3. Starting with the denominator, there are two words that include the prefix $a(48-\mathrm{a})$. For one of those words, the $a$ suffix is redundant with respect to number makering, i.e. its $I_{\mathrm{NUM}}$ is a superset of another formative within that word (48-b). Yet, for the other word this is not the case (48-d). Thus, there are exactly one example of redundancy involving $a$ out its total of two occurrences, thus we say that its redundancy value is one half (48-e). That is, it is redundant half of the time.

(48) a. $\quad|\{\omega: a \in W\}|=\mid\{<a$, ray, en $\rangle,<a$, ray,inon $\rangle\} \mid=2$

b. $\quad I_{\mathrm{NUM}}(a) \supset I_{\mathrm{NUM}}($ inon $)$

c. $I_{\mathrm{NUM}}(a) \not \supset I_{\mathrm{NUM}}($ en $)$

d. $\quad\left|\left\{\omega: I_{\mathrm{NUM}}(a) \supset \bigcap I_{\mathrm{NUM}}(b)\right\}\right|=1$

e. $\bar{R}_{\mathrm{NUM}}(a)=1 / 2=0.5$

We also may wish to calculate a formative total redundancy value for an entire lexeme which we would write as $\bar{R}_{\lambda}$. This is simply the sum of the number of redundant 
values for all the $I_{\sigma}$ sets associated with the formative over all words containing that formative multiplied by the number of $I_{\sigma}$ sets (49).

$$
\bar{R}_{\lambda}(a)=\frac{\left|\left\{\omega: I_{\sigma}(a) \supset \bigcap \operatorname{dist}_{\sigma}(b)\right\}+\ldots+\left\{\omega: I_{\sigma}(a) \supset \bigcap \operatorname{dist}_{\sigma}(b)\right\}\right|}{|\{\omega: a \in W\}| \cdot|\operatorname{dim}(a)|}
$$

To illustrate, let us consider the ja suffix in our Ngarnka example. We have already established its relevant dimensions as gender and number (50-a), therefore we can expect to need to measure its redundancy for both these values. We see that the formative occurs in two distinct cells (50-b) and thus we must check redundancy for two feature across two cells, that gives us our denominator of 4 (50-c). Checking redundancy, we can see that $j a$ is redundant with respect to gender in one case but not the other (50-d)(50-e). Despite being informative for number, $j a$ is always redundant with respect to number given kuny. Not that ja is an example of unilateral redundancy for masculine gender bilateral redundancy for number. Finally, since now see that $j a$ is redundant in three of the four instances where it provides information, it has a redundancy value $\operatorname{barR}_{\lambda}(j a)$ of $3 / 4$ or 0.75 .

$$
\begin{aligned}
& \text { a. }|\operatorname{dim}(a)|=\mid\{\text { GEN, NUM }\} \mid=2 \\
& \text { b. }|\{\omega: a \in W\}|=\mid\{\langle\text { ni, yangka, kuny, ja }>,<\text { na, yangka, kuny, ja }>\} \mid=2 \\
& \text { c. }|\{\omega: a \in W\}| \cdot|\operatorname{dim}(a)|=4 \\
& \text { d. } \quad I_{\mathrm{GEND}}(j a) \supset I_{\mathrm{GEND}}(n i): j a, n i \in<n i, \text { yangka, kuny, ja }> \\
& \text { e. } \quad I_{\mathrm{GEND}}(j a) \nsupseteq I_{\mathrm{GEND}}(n a): j a, n a \in<n a, \text { yangka, kuny, ja }> \\
& \text { f. } \quad I_{\mathrm{NUM}}(j a)=I_{\mathrm{NUM}}(k u n y): \text { ja, kuny } \in<n i, \text { yangka, kuny, ja }> \\
& \text { g. } \quad I_{\mathrm{NUM}}(j a)=I_{\mathrm{NUM}}(k u n y): \text { ja, kuny } \in<n a, \text { yangka, kuny, ja }> \\
& \text { h. } \quad \bar{R}_{\lambda}(j a)=3 / 4=0.75
\end{aligned}
$$

\section{Summary}

The typology of exponence, i.e. how information is indicated through patterns in morphological paradigms, has largely remained based on Matthews (1974). More recent work has explored exactly how rich certain types are in empirical, typological and historical domains (Caballero and Harris, 2012; Harris, 2017). Yet the categories of the typology largely remain the same as those in the earlier work. In this paper, we have shown that by taking a typological-functional perspective on exponence, i.e. informativeness, a much broader picture emerges. This paper has proposed the term verbose exponence for this perspective.

We have seen how the perspective of verbose exponence naturally captures both the existing typological observations about multiple exponence but also incorporates 
phenomena such as distributed exponence into a single cross-linguistic framework. This typology is sophisticated enough to capture existing types but shows how they can intersect resulting in complex networks of exponence relations.

In this paper, the concept of morphological information was formalised as 'informativeness with respect to a particular feature.' This was defined within a abstract model that demonstrated how traditional approaches to inflectional typology can be formalised using set-theory. This formalised approach allows for unambiguous typological definitions. It is also sufficiently precise to implement computational and quantitative measures of typological phenomena.

I propose that this model opens up numerous avenues of future research. Most prominent of these is a full characterisation of the typological space of exponence in explicit terms. If sufficiently precise enough to allow for a computational implementation, and given appropriately coded up datasets, then this opens up opportunities for large scale typological work to be conducted with the levels of precision typically only found in typological studies conducted on carefully hand-curated sample of examples. Further, these models allow for sophisticated quantitative measures of cross-linguistic phenomena which might provide a basis for moving linguistic typology from 'observation to explanation' (Round and Corbett, 2019, 501). For instance, work has begun attempting to explain redundancy in Yam languages using the definitions presented here and models from the evolutionary dynamics of genes applied to morphological structure (Carroll, 2021).

\section{Abbreviations}

Non-standard abbreviations used in this article:

LPL large plural

NPL non-plural

NSG non-singular

\section{Acknowledgements}

Versions of this paper were read at the Annual Meeting of the Linguistics Association of Great Britain, University of Kent, Canterbury, 7 September 2017; Conference of the Association for Linguistic Typology, Australian National University, Canberra, 12 December 2017; New Fields for Morphology Workshop, University of Surrey, Guildford, 2 November 2018; 'New approaches to the typology of inflectional systems workshop', 
University of Chicago Center in Paris, 16 November 2018; American Associations for the Advancement of Science Annual Meeting, Washington, DC, 15 February 2019; Linguistics Seminar, SOAS, London, 28 February 2019; Linguistics Lunch at the Laboratoire de Linguistique Formelle, Paris Diderot University, 1 March 2019. I am grateful to those present for helpful suggestions and questions as well as the generous support from the individuals and institutions where I presented an invited presentation. For valuable comments on the different versions of this paper and development the ideas within, I am thankful to Matthew Baerman, Oliver Bond, Greville Corbett, Nick Evans, Tim Feist, Borja Herce, Jérémy Pasquereau, Tatiana Reid, Kristian Roncero and Helen Sims-Williams. I am especially grateful to Erich Round for the many constructive comments on early versions of this paper and to Olivier Bonami and Sacha Beniamine for fruitful discussions on modelling inflection for typology. I am also grateful to all the anonymous referees and the editors at Morphology for their numerous constructive suggestions.

\section{References}

Bickel B (2007) Typology in the 21st century: Major current developments. Linguistic Typology 11(1):239-251

Blevins JP (2016) Word and paradigm morphology. Oxford: Oxford University Press

Bond O (2012) A base for canonical negation. In: Brown D, Chumakina M, Corbett GG (eds) Canonical morphology and syntax, Oxford: Oxford University Press, pp 20-47

Bond 0 (2019) Canonical Typology. In: Audring J, Masini F (eds) The Oxford handbook of morphological theory, Oxford: Oxford University Press, pp 408-431

Bond O, Corbett GG, Chumakina M, Brown D (2016) Archi: Complexities of agreement in cross-theoretical perspective. Oxford: Oxford University Press

Caballero G, Harris AC (2012) A working typology of multiple exponence. In: Kiefer F, Ladányi M, Siptár P (eds) Current issues in morphological theory: (Ir)regularity, analogy and frequency., Amsterdam: John Benjamins Publishing Company

Caballero G, Kapatsinski V (2015) Perceptual functionality of morphological redundancy in Choguita Rarámuri (Tarahumara). Language, Cognition and Neuroscience 30(9):1134-1143

Carroll MJ (2016) The Ngkolmpu Language with special reference to distributed exponence. PhD thesis, School of Culture, History \& Language, College of Asia \& the Pacific, The Australian National University 
Carroll MJ (2020) The morphology of Yam languages. In: Aronoff M (ed) The Oxford Research Encyclopedia of Linguistics, Oxford: Oxford University Press

Carroll MJ (2021) Explaining redundancy in linguistic morphology: evidence from Yam and Kartvelian. In: Cultural Evolution Society Conference 2021, Sapporo. 9th-11th June 2021.

Carroll MJ (Forthcoming) Yei sketch grammr cameo.

Coates R (2000) Exponence. In: Morphologie / Morphology, Berlin: Walter de Gruyter

Corbett GG (2012) Features. Cambridge Textbooks in Linguistics, Cambridge: Cambridge University Press

Corbett GG (2015) Morphosyntactic complexity: A typology of lexical splits. Langauge 1(91):145-193

Cowan H (1965) Grammar of the Sentani Language with specimen texts and vocabulary. B: Springer-Science+Business Media

Dondorp A, Shim JW (1997) Wipi grammar essentials. Unpublished MS (Formatted and published online by Ruth Wester November 2013), URL https://www.sil.org/system/files/reapdata/12/64/00/ 126400344619797297927934972982934574861/Wipi_Grammar_Essentials .pdf

Evans N (2015) Inflection in Nen. In: Baerman M (ed) The Oxford handbook of inflection, Oxford: Oxford University Press

Evans N, Arka W, Carroll M, Choi YJ, Döhler C, Gast V, Kashima E, Mittag E, Quinn K, Schokken D, Siegel J, Tama P, van Tongeren C (2017) The languages of southern NewGuinea. In: The Languages and Linguistics of the New Guinea Area, Berlin: Mouton de Gruyter

Halmos PR (1960) Naive set theory. New York: Springer-Verlag

Harris AC (2017) Multiple exponence. Oxford: Oxford University Press

Lawton JH, Brown VK (1994) Redundancy in ecosystems. In: Schultze H ED \& Mooney (ed) Biodiversity and ecosystem function, Berlin: Springer-Verlag, pp 255-270

Matthews PH (1974) Morphology. Cambridge Textbooks in Linguistics, Cambridge: Cambridge University Press

McFarland T (2009) The verbal morphology of Totonaco de Filomeno Mata. PhD thesis, University of California, Berkeley 
Nowak MA, Boerlijst MC, Cooke J, Smith JM (1997) Evolution of genetic redundancy. Nature 388(6638):167-171

Osgarby DJ (2014) Nominal morphology of Ngarnka, Northern Territory (Australia). Master's thesis, University of Queensland

Partee BH, ter Meulen A, Wall RE (1990) Mathematical methods in linguistics. Dordrecht: Kluwer Academic Publishers

Partridge D (1981) Information theory and redundancy. Philosophy of Science 48(2):308-316

Reid N (1990) Ngan'gityemerri: a language of the Daly River region, Northern Territory of Australia. PhD thesis, Australian National University

Round E, Corbett GG (2019) Comparability and measurement in typological science: the bright future for linguistics. Linguistic Typology 24(4):489-525

Stump G (2016) Inflectional paradigms: content and form at the syntax-morphology interface. Cambridge: Cambridge University Press 